\title{
Cloning and expression of the EsxA gene and analysis of the growth- promoting effects of the encoded protein on rice seedlings
}

Wen-qing Yu ${ }^{1,2,3}$, Xin Wang ${ }^{4}$, Yi-cong Tang ${ }^{4}$, Feng-chao Yan², Wen-zhi Liu ${ }^{1,2 *}$, Gui-ping Zheng ${ }^{3}$, Dong-mei Yin

Abstract: An EsxA-encoding gene was previously identified in the genome of the plant growthpromoting rhizobacterium Paenibacillus terrae strain NK3-4. The EsxA gene was cloned and expressed in Pichia pastoris, after which the effects of the EsxA protein on rice seedling growth were analyzed to determine whether EsxA contributes to the plant growth-promoting activity of strain NK3-4. The EsxA gene was successfully cloned from the NK3-4 genome and ligated to the eukaryotic expression vector $\mathrm{pPICZ} \alpha \mathrm{A}$. The resulting $\mathrm{pPICZ} \alpha \mathrm{A}-E s x A$ recombinant plasmid was inserted into $P$. pastoris cells, and EsxA gene expression in the yeast cells was confirmed. The treatment of seedbuds with the EsxA protein increased the root length by 1.35-times, but decreased the bud length. Additionally, in rice seedlings treated with EsxA, the root and shoot lengths increased by 2.6- and 1.7-times, respectively. These findings imply that EsxA is important for the promotion of rice plant growth by $P$. terrae strain NK3-4. Furthermore, the construction of the EsxA gene expression vector and the engineered strain may be useful for future investigations of the mechanism underlying the plant growth-promoting effects of EsxA, with implications for the application of EsxA for regulating plant growth.

Key words: EsxA, Paenibacillus terrae, gene cloning, gene expression, growth promotion, rice

\section{Introduction}

Early secreted antigenic target of $6 \mathrm{kDa}$ (ESAT-6), which is a member of the WXG super family, is encoded by the EsxA gene. This protein, which comprises approximately 100 amino acids, belongs to the Type VII secretion system. Additionally, it forms a dimer structure under natural conditions. The EsxA protein was first identified in the animal pathogen Mycobacterium tuberculosis (Pollock

\footnotetext{
*Correspondence: liuwz19801005@sina.com

${ }^{1}$ College of Life Sciences, Shangrao Normal University, Shangrao Agricultural Technology Innovation Institute, Shanrao Jiangxi 334001, China

${ }^{2}$ Heilongjiang Bayi Agricultural University, Daqing Heilongjiang, 163319, China

${ }^{3}$ Heilongjiang Academy of Agricultural Reclamation Sciences, Haerbin 150038, China

${ }^{4}$ China Quality Certification Centre, Beijing, 100070, China
} 
and Andersen, 1997), and was revealed to be important for pathogenicity (Berthet et al. 1998; Ulrichs et al. 1998). The protein was subsequently detected in other animal pathogens (Schulthess et al. 2012; Ma et al. 2015), and has been studied as a virulence factor for bacterial pathogens. However, EsxA is not a simple virulence factor. In addition to being important for the pathogenicity of animal pathogens, it can also induce an immune response in animals (Yi et al. 2018). For example, Staphylococcus aureus EsxA can promote antibody production in patients infected with this bacterium (Zhou et al. 2013).

In an earlier study, we identified an EsxA gene in the genome of the plant growth-promoting rhizobacterium Paenibacillus terrae strain NK3-4 (Yu et al. 2019a). A phylogenetic analysis based on the EsxA amino acid sequences of Paenibacillus strains revealed that EsxA genes are widely distributed in plant growth-promoting Paenibacillus strains (Yu, 2019). This implies that EsxA in Paenibacillus species may be functionally distinct from the corresponding proteins in the bacterial pathogens of animals. However, there are no reports describing the functions of EsxA in Paenibacillus strains or in other non-pathogenic bacteria, and it is unclear whether EsxA contributes to the plant growth-promoting effects of specific rhizobacteria. The objectives of this study were to clone the EsxA gene in the P. terrae NK3-4 genome for a subsequent expression in Pichia pastoris cells and an examination of the influence of EsxA on rice growth. The results of this study may be useful for clarifying the mechanism by which Paenibacillus strains, including NK3-4, promote plant growth.

\section{Materials and methods}

\section{Materials}

The plant growth-promoting rhizobacterium P. terrae strain NK3-4 used in this study was isolated and identified in one of our earlier studies (Yu et al. 2014), and was maintained in our laboratory. Pichia pastoris $\mathrm{KM} 71 \mathrm{H}$ and the pPICZ $\alpha \mathrm{A}$ vector were provided by the Institute of Plant Protection, Chinese Academy of Agricultural Sciences. Tobacco (Nicotiana tabacum), tomato (Solanum 
lycopersicum), radish (Scrophularia ningpoensis), and pakchoi (Brassica rapa L. ssp. chinensis) plants were grown in pots.

\section{EsxA gene cloning, expression, and purification}

Extraction of strain NK3-4 genomic DNA

Genomic DNA was extracted from strain NK3-4 using the Bacterial Genomic DNA Extraction kit (Solarbio Technology Co., Ltd., Beijing). The extracted DNA was analyzed by $1 \%$ agarose gel electrophoresis. Additionally, the $\mathrm{OD}_{260} / \mathrm{OD}_{280}$ ratio was calculated to determine whether the DNA quality was appropriate for the subsequent experiments.

\section{Cloning of the EsxA gene}

Primer design: The following primers were designed according to the EsxA gene sequence in the NK3-4 genome database. The EcoRI/XbaI restriction sites as well as protective bases were added to both ends of the primers.

primer F: 5'-CCGGAATTCATGGCAGGACGCATTTTAATTACC-3';

primer R: 5'-GCTCTAGACCCTTCGTTTGGTCAACAGTACGGAA-3'

PCR amplification of the EsxA gene: The PCR amplification was completed in a 50- $\mu \mathrm{L}$ solution comprising $25 \mu \mathrm{L} 2 \times$ HiFiMix I, $20 \mu \mathrm{L} \mathrm{ddH}_{2} \mathrm{O}, 1 \mu \mathrm{L}$ DNA template, and $2 \mu \mathrm{L}$ each primer $(10 \mu \mathrm{M})$. The PCR program was as follows: $95{ }^{\circ} \mathrm{C}$ for $5 \mathrm{~min} ; 35$ cycles of $94{ }^{\circ} \mathrm{C}$ for $30 \mathrm{~s}, 56{ }^{\circ} \mathrm{C}$ for $30 \mathrm{~s}$, and $72{ }^{\circ} \mathrm{C}$ for $1 \mathrm{~min} ; 72{ }^{\circ} \mathrm{C}$ for $10 \mathrm{~min}$. The PCR product was maintained at $4{ }^{\circ} \mathrm{C}$ until it was analyzed and purified.

\section{Purification of the PCR product}

The PCR product was analyzed by gel electrophoresis and then purified using the QIAquick Gel Extraction Kit (Qiagen, Frankfurt, Germany). The quality and concentration of the recovered DNA were checked, after which the DNA was stored at $-20^{\circ} \mathrm{C}$.

\section{Multiplication of the pPICZaA vector}

The pPICZ $\alpha \mathrm{A}$ vector was inserted into competent Escherichia coli Trans1-T1 cells (Quanshijin Biotechnology Co., Ltd., Beijing, China). Positive transformants screened on solid LA medium 
containing bleomycin $(500 \mu \mathrm{g} / \mathrm{mL})$ were used to inoculate liquid LB medium supplemented with bleomycin $(500 \mu \mathrm{g} / \mathrm{mL})$. The pPICZ $\alpha \mathrm{A}$ vector was purified from the E. coli cells using a commercial plasmid extraction kit, after which the vector quality was checked and the concentration was determined. The purified pPICZ $\alpha$ A was stored at $-20{ }^{\circ} \mathrm{C}$.

\section{Digestion and purification of pPICZ $\alpha A$ and the EsxA gene}

The EsxA gene and pPICZ $\alpha \mathrm{A}$ vector were digested with EcoRI and XbaI in a $50-\mu \mathrm{L}$ solution consisting of $15 \mu \mathrm{L}$ EsxA sequence amplified by PCR or the pPICZ $\alpha$ A vector, $1 \mu \mathrm{L}$ EcoRI and XbaI (1 U), $5 \mu \mathrm{L}$ buffer [10×M: $100 \mathrm{mM}$ Tris- $\mathrm{HCl}(\mathrm{pH} 7.5), 100 \mathrm{mM} \mathrm{MgCl} 2,10 \mathrm{mM}$ dithiothreitol, and

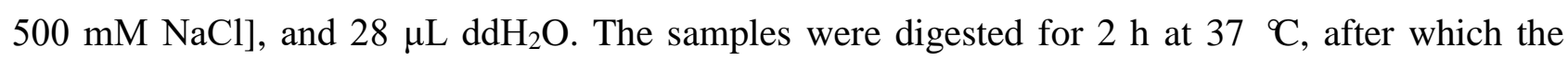
digested products were analyzed by $1 \%$ agarose gel electrophoresis and purified.

\section{Ligation of the EsxA gene and the pPICZaA vector}

The digested pPICZ $\alpha \mathrm{A}$ vector and EsxA gene were ligated with T4 ligase in a $10-\mu \mathrm{L}$ solution containing $2 \mu \mathrm{L}$ pPICZ $\alpha \mathrm{A}$ (100 ng), $4 \mu \mathrm{L}$ EsxA (17 ng), $1 \mu \mathrm{L} 10 \times$ ligase buffer, $0.2 \mu \mathrm{L}$ T4 ligase (1 $\mathrm{U})$, and $2.8 \mu \mathrm{L} \mathrm{ddH_{2 }} \mathrm{O}$. The ligation was completed during a 10 -min incubation at $25^{\circ} \mathrm{C}$.

\subsubsection{Subcloning of the pPICZaA-EsxA recombinant plasmid and screening of positive clones}

The pPICZ $\alpha \mathrm{A}-E s x A$ recombinant plasmid was inserted into competent $E$. coli Trans1-T1 cells, after which positive transformants were screened on solid LA medium containing bleomycin. A single positive colony was used to inoculate liquid LB medium containing bleomycin $(1,000 \mu \mathrm{g} / \mathrm{mL})$ in a centrifuge tube, which was then incubated for $1 \mathrm{~h}$ at $37^{\circ} \mathrm{C}$ with shaking. The pPICZ $\alpha \mathrm{A}-E s x A$ recombinant plasmid was extracted from the E. coli cells and sequenced to confirm its accuracy. The transformants containing pPICZ $\alpha \mathrm{A}-E s x A$ were multiplied, after which the recombinant plasmid was purified and its quality and concentration were determined by $1 \%$ agarose electrophoresis.

\section{Linearization of pPICZaA-EsxA}

The pPICZ $\alpha \mathrm{A}-E s x A$ recombinant plasmid was linearized via a digestion with PmaI in a $50-\mu \mathrm{L}$ solution comprising $2 \mu \mathrm{L}$ PmaI (2 U), $5 \mu \mathrm{L}$ CutSmart buffer, and $43 \mu \mathrm{L}$ pPICZ $\alpha \mathrm{A}-E s x A$. The digestion was completed during a 2.5 -h incubation at $37^{\circ} \mathrm{C}$. The linearized product solution was concentrated to $15 \mu \mathrm{L}$ and stored at $-20{ }^{\circ} \mathrm{C}$. 


\section{Preparation of competent Pichia pastoris KM71H cells}

Pichia pastoris $\mathrm{KM} 71 \mathrm{H}$ cells $(10 \mu \mathrm{L})$ stored in glycerol were recovered on ice and then used to inoculate $10 \mathrm{~mL}$ YPD medium in a $100 \mathrm{~mL}$ flask. The cells were cultured overnight at $37{ }^{\circ} \mathrm{C}$ with shaking (170 rpm). A $100-\mu \mathrm{L}$ aliquot of the cells was used to inoculate $500 \mathrm{~mL}$ YPD medium in a 2 L flask. The cell culture was incubated overnight at $37{ }^{\circ} \mathrm{C}$ with shaking $(170 \mathrm{rpm})$, after which the OD 595 was 1.3-1.5. Competent cells were prepared as follows: (1) $50 \mathrm{~mL}$ KM71H cell suspension was centrifuged at $845 \times \mathrm{g}$ for $5 \mathrm{~min}$ at $4{ }^{\circ} \mathrm{C}$; (2) After discarding the supernatant, the cells were resuspended in $50 \mathrm{~mL}$ sterile $\mathrm{ddH}_{2} \mathrm{O}$ pre-cooled on ice. The cell suspension was centrifuged again; (3) After discarding the supernatant, $25 \mathrm{~mL}$ sterile water pre-cooled on ice was added to resuspend the cells, after which the cell suspension was centrifuged again; (4) The supernatant was discarded and the cells were resuspended in $2 \mathrm{~mL} 1.0 \mathrm{M}$ sorbitol pre-cooled on ice and then centrifuged again; (5) The cells were finally resuspended in $100 \mu \mathrm{L} 1.0 \mathrm{M}$ sorbitol pre-cooled on ice.

\section{Transformation of competent Pichia pastoris cells with the linearized pPICZ $\alpha A-E s x A$}

Competent $P$. pastoris cells $(80 \mu \mathrm{L})$ were added to an electroporation cup pre-cooled on ice, to which $100 \mu \mathrm{L}$ linearized pPICZ $\alpha \mathrm{A}-E s x A$ was added. The cells were electroporated for $4 \mathrm{~ms}$ at $1.5 \mathrm{kw}, 25$ $\mu \mathrm{F}$, and $200 \Omega$, after which $1.0 \mathrm{~mL} 1.0 \mathrm{M}$ sorbitol was added to the electroporation cup, which was incubated undisturbed for $2 \mathrm{~h}$ at $28^{\circ} \mathrm{C}$.

Screening of positive Pichia pastoris clones carrying pPICZ $\alpha A-E s x A$

A $500 \mu \mathrm{L}$ suspension of yeast cells transformed with linearized pPICZ $\alpha \mathrm{A}-E s x A$ was spread on solid YPDS medium containing $500 \mu \mathrm{g} / \mathrm{mL}$ bleomycin. After a 5-day incubation at $28{ }^{\circ} \mathrm{C}$, positive clones were selected for a PCR analysis.

\section{Induction of EsxA gene expression}

A positive transformant was used to inoculate liquid BMGY medium, which was then incubated at $28{ }^{\circ} \mathrm{C}$ with shaking $(250 \mathrm{rpm})$ until the $\mathrm{OD}_{595}$ reached 2-6 $(16-18 \mathrm{~h})$. The culture was centrifuged at $845 \times \mathrm{g}$ at room temperature, after which the supernatant was discarded and the cells were resuspended in 1/10 volume of the original BMGY medium. The culture was then incubated as before. At 24-h intervals, $100 \%$ methanol was added to the cell culture for a final concentration of $0.5 \%$. Cell samples were collected every $24 \mathrm{~h}$ after methanol was first added. Methanol was added four times and cell samples were collected four times. Each cell sample was centrifuged at $845 \times \mathrm{g}$ for 5 min. The supernatant was transferred to a new centrifuge tube and stored at $-80{ }^{\circ} \mathrm{C}$. After inducing Esx A 
gene expression, the abundance of the expressed protein in the supernatant was analyzed by SDSPAGE to determine the optimal induction time.

\section{Identification of EsxA by mass spectrometry}

The target band in the SDS-PAGE gel was excised and analyzed with the 5800 MALDI-TOF/TOF system (AB SCIEX) using the 384 Opti-TOF sample plate $(123 \mathrm{~mm} \times 81 \mathrm{~mm})($ AB SCIEX). The steps are summarized as follows:

(1) Enzymatic hydrolysis: A sequencing-grade trypsin solution was added to the EP tube containing the excised SDS-PAGE gel strip. The enzymatic hydrolysis of the sample was completed during a 20 -h incubation at $37{ }^{\circ} \mathrm{C}$. Following the trypsin digestion, $100 \mu \mathrm{L} 60 \%$ acetonitrile $(\mathrm{ACN}) / 0.1 \%$ trifluoroacetic acid (TFA) was added to the tube, after which the sample was sonicated for $15 \mathrm{~min}$ and then lyophilized.

(2) Mass spectrometry analysis: $1 \mu \mathrm{L}$ dissolved sample was spotted on the sample plate. After the solvent dried, $0.6 \mu \mathrm{L}$ supersaturated cinnamic acid matrix solution (50\% ACN/0.1\% TFA) was added to the corresponding target position and dried. The sample plate was treated with nitrogen gas and then placed in the sample injection target slot of the 5800 MALDI-TOF/TOF instrument (AB SCIEX). The Nd:YAG laser was used at a wavelength of $349 \mathrm{~nm}$. The acceleration voltage was $2 \mathrm{kV}$. The positive ion mode and the automatic data acquisition mode were applied to collect data. The scanning range of the primary mass spectrum was $800-4,000$ Da. A precursor ion with a signal-to-noise ratio greater than 50 was used for the secondary mass spectrum (MS/MS) analysis. Ten precursor ions were selected for each sample point, and the MS/MS spectra were derived from an accumulation of 2,500 laser shots. The collision energy was $2 \mathrm{kV}$, and the CID was turned off.

(3) Protein database search: The original mass spectrometry data were used for database screening with the Mascot 2.2 software to identify proteins. The search parameters were as follows: (i) Database: Paenibacillus UniProt self-built library (strain NK3-4 predicted protein database);

(ii) Search type: joint (MS+MS/MS); (iii) Enzyme: trypsin; (iv) Fixed correction: Carbamidomethyl (C); (v) Dynamic correction: Oxidation (M); (vi) Quantity: monoisotope; (vii) Protein quantity: unlimited; (viii) Peptide quality limit: \pm 100 ppm; (ix) Fragment limit: \pm 0.4 Da; (x) peptide charge: $1+$; (xi) maximum missed detection: 1 . 


\section{Analysis of the induction of the plant hypersensitive response (HR) and reactive oxygen species (ROS) burst by EsxA}

\section{Induction of the $H R$}

The expressed EsxA was purified by nickel column chromatography. Specifically, the protein was collected in approximately $30 \mathrm{~mL}$ eluant. After removing salt and concentrating by ultrafiltration, a 5-mL protein solution $(2.0 \mathrm{mg} / \mathrm{mL})$ was obtained. Tobacco, tomato, radish, and pakchoi were used as the test plants. Specifically, a previously described HR test was conducted (Yu et al. 2019b). Briefly, $20 \mu \mathrm{L}$ EsxA solution $(500 \mu \mathrm{g} / \mathrm{mL})$ was injected into one side of each leaf, whereas bovine serum albumin (BSA) was injected into the other side as a control treatment. Additionally, another tobacco leaf injected with BSA served as a control for the ROS burst test. Analyses were repeated three times.

\section{Induction of the ROS burst}

At $24 \mathrm{~h}$ after the injections, the EsxA- and BSA-infiltrated leaves and the untreated leaves growing above the treated leaves were collected and rinsed with $\mathrm{ddH}_{2} \mathrm{O}$. They were then immersed in a 3,3'diaminobenzidine hydrochloride solution $(1 \mathrm{mg} / \mathrm{mL}, \mathrm{pH} 3.8)$. The samples were incubated undisturbed overnight in darkness, after which they were immersed in a solution comprising ethanol and glycerin $[9: 1(\mathrm{v} / \mathrm{v})]$ and incubated in a boiling water bath to decolorize the chlorophyll in the leaves. After the decolorization, $75 \%$ glycerin was added to the leaf surface to flatten the leaves, which were then examined with a microscope. The detection of obvious brownish-red patches exclusively in the leaves of EsxA-infiltrated plants (i.e., not in the control plants) indicated that EsxA induced the ROS burst.

\section{Determination of the effects of EsxA on rice seedling growth}

The EsxA purified by nickel column chromatography was dissolved in PBS buffer. The seed-bud dipping method and the seedling dipping method were used to treat rice (Oryza sativa L. ssp. japonica) plants to determine the effects of EsxA on rice seedling growth.

\section{Seed-bud dipping method}

Coarse gravel ( $4.0 \mathrm{~cm}$ thick) was washed, sterilized, and added to germination pots $(10 \mathrm{~cm}$ diameter; $5 \mathrm{~cm}$ height). Rice seed-buds [i.e., the bud (1 mm long) has broken through the seed coat] were uniformly sown on the gravel surface in the pots (100 seed-buds per pot). The seed-buds and the 
gravel were sprayed with an EsxA solution $[100 \mu \mathrm{g} / \mathrm{mL}$ in $50 \mathrm{mM}$ PBS (pH 7.5)]. The buds were covered with sterilized gravel $(0.5 \mathrm{~cm}$ thick), which was then sprayed with the EsxA solution to ensure the seed-buds remained moist. The germination pots were covered with clear vented lids and maintained at $28^{\circ} \mathrm{C}$ for $24 \mathrm{~h}$ in an incubator. They were then transferred to a phytotron and incubated at $30^{\circ} \mathrm{C}$ for $24 \mathrm{~h}$, with a 12-h light cycle. After the incubation period, the shoot and root lengths were determined. Control samples were treated with PBS instead of the EsxA solution. The analysis was completed with three replicates.

\section{Seedling dipping method}

Rice seeds were germinated and placed in germination pots lined with sterile filter paper, with each pot containing 100 germinated seeds. Distilled water $(10 \mathrm{~mL})$ was poured into all pots, which were then covered with lids and maintained at $28{ }^{\circ} \mathrm{C}$ for $24 \mathrm{~h}$ in an incubator. The seedlings in each pot were then sprayed with $1 \mathrm{~mL}$ EsxA solution $(100 \mu \mathrm{g} / \mathrm{mL})$. Control seedlings were sprayed with 50 $\mathrm{mM}$ PBS ( $\mathrm{pH}$ 7.5). The pots were incubated at room temperature (day: $25^{\circ} \mathrm{C}$; night: $18{ }^{\circ} \mathrm{C}$ ) without a lid for $48 \mathrm{~h}$, with a 12-h light cycle. After the incubation period, the shoot and root lengths were determined. The analysis was completed with three replicates.

\section{Data analysis}

The SPSS 13.0 software (Chicago, USA) was used to perform a one-way ANOVA to assess the significance of the differences between two variables. Additionally, a two-way ANOVA was performed for independent replicates of the same experiment and variables in two-way trials. Multiple comparisons (one-way ANOVA and LSD) were used to evaluate the significance of the differences among variables. Bar graphs were prepared using Excel and GraphPad Prism (version 6.0) software.

\section{Results}

Cloning and expression of the EsxA gene and the functional characterization of the encoded protein

Genomic DNA extraction and PCR amplification of the EsxA gene

Paenibacillus terrae strain NK3-4 genomic DNA was analyzed by agarose gel electrophoresis and spectrophotometrically. The genomic DNA bands were clear and there were no obvious signs of degradation (Figure 1A). The $\mathrm{OD}_{260} / \mathrm{OD}_{280}$ ratio was between 1.8 and 2.0. The genomic DNA was 
free of proteins and RNA. These results confirmed the quality of the genomic DNA was appropriate for the subsequent PCR amplification. The analysis of the amplified product by agarose gel electrophoresis revealed a fragment slightly longer than $250 \mathrm{bp}$ was cloned from the genomic DNA, which was consistent with the size of the EsxA gene (Figure 1B). Thus, the EsxA sequence was successfully amplified by PCR. After purifying the amplified fragment from the gel, it was once again analyzed by agarose gel electrophoresis. The corresponding band was bright and the DNA concentration was sufficiently high. Additionally, the pPICZ $\alpha$ A vector was successfully multiplied and purified (Figure 1C). The amplified EsxA gene sequence and the pPICZ $\alpha \mathrm{A}$ vector were suitable for the following experiments.
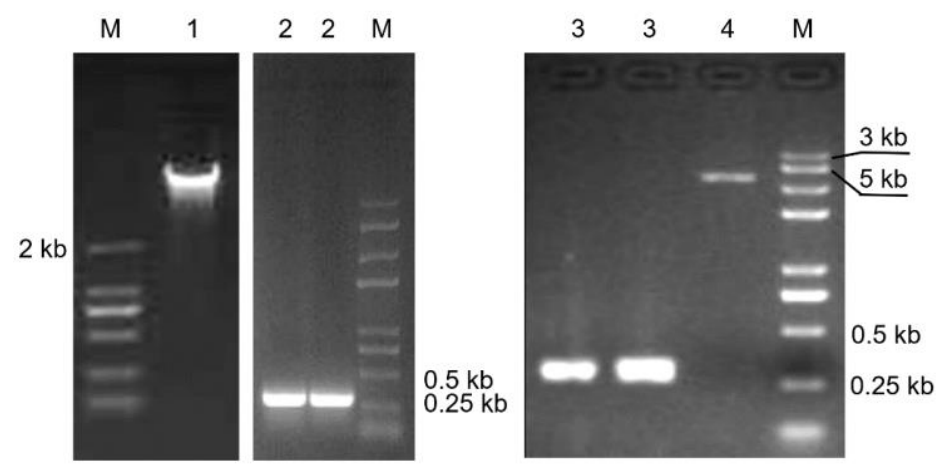

Fig. 1 Electrophoretic analysis of the extracted strain NK3-4 genomic DNA (A), EsxA gene amplification (B), and EsxA gene and vector preparation (C).

Note: M: marker; 1: genomic DNA; 2 and 3: amplified EsxA gene and the amplified product recovered from the agarose gel, respectively; 4: pPICZ $\alpha$ A vector

\section{Construction and linearization of the pPICZaA-EsxA recombinant plasmid}

The amplified EsxA gene and pPICZ $\alpha$ A digested with EcoRI and XbaI were ligated. The agarose gel electrophoresis analysis of the ligation product indicated that the empty vector (pPICZ $\alpha \mathrm{A})$ and the pPICZaA-EsxA recombinant plasmid comprised 3,000-5,000 bp, which was consistent with the predicted sizes. Moreover, the empty vector migrated slightly faster than pPICZ $\alpha \mathrm{A}-E s x A$, implying the recombinant plasmid was successfully constructed (Figure 2A). After pPICZ $\alpha \mathrm{A}-E s x A$ was digested, it migrated through the agarose gel significantly more slowly than the circular recombinant plasmid, indicating that pPICZ $\alpha \mathrm{A}-E s x A$ had been successfully linearized (Figure 2B). 


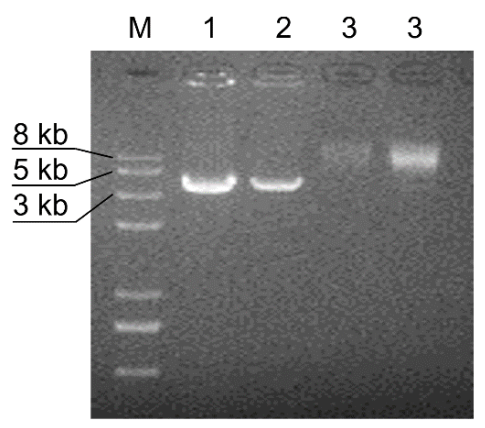

Fig. 2 Electrophoretic analysis of the construction and linearization of pPICZ $\alpha \mathrm{A}-E s x A$.

Note: 1, 2, and 3: pPICZ $\alpha \mathrm{A}, \mathrm{pPICZ} \alpha \mathrm{A}-E s x A$, and linearized pPICZ $\alpha \mathrm{A}-E s x A$, respectively; M: marker

\section{Transformation of yeast cells with pPICZ $\alpha A-E s x A$ and analysis of the induced EsxA expression}

After examining transformants by colony PCR using EsxA gene-specific primers, an agarose gel electrophoresis analysis revealed an amplified product that was longer than $250 \mathrm{bp}$, indicating the cells were correctly transformed with pPICZ $\alpha \mathrm{A}-E s x A$. The confirmed transformants were cultured and induced for 24, 48, 72, and $96 \mathrm{~h}$. An SDS-PAGE analysis indicated that specific proteins were expressed during different induction periods, with molecular weights ranging from 10 to $15 \mathrm{kDa}$. The protein expression levels were significantly higher at 72 and $96 \mathrm{~h}$ than at 24 and $48 \mathrm{~h}$ (Figure 3).

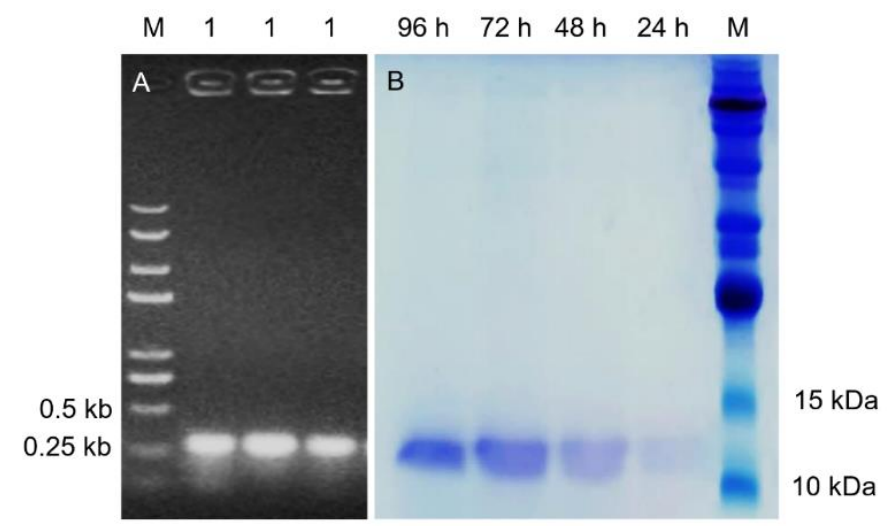

Fig. 3 Detection of transformants by PCR (A) and an analysis of expressed proteins by SDS-PAGE (B).

Note: in A: 1: PCR analysis of transformants carrying the EsxA gene; in B: 24, 48, 72, and 96 h: induction periods; M: marker

Identification of EsxA by mass spectrometry

The band in the SDS-PAGE gel with the expected size for EsxA was excised from the gel and analyzed by mass spectrometry, which confirmed the expressed protein was EsxA. Most of the amino 
acids in this protein have been identified. The five detected peptide fragments were ILITPEQVDQVANQF, EQSQQIVSSLTQSIS, GMEGQWEGMTKQR, QRFFQEFQEASK, and TLNSISQELTAI. The MS/MS spectra of two peptides and the distribution of these peptides in EsxA are presented in Figure 4. The amino acid sequence included the conserved WXG motif Trp44(W)-Glu45(E)-Gly46(G).

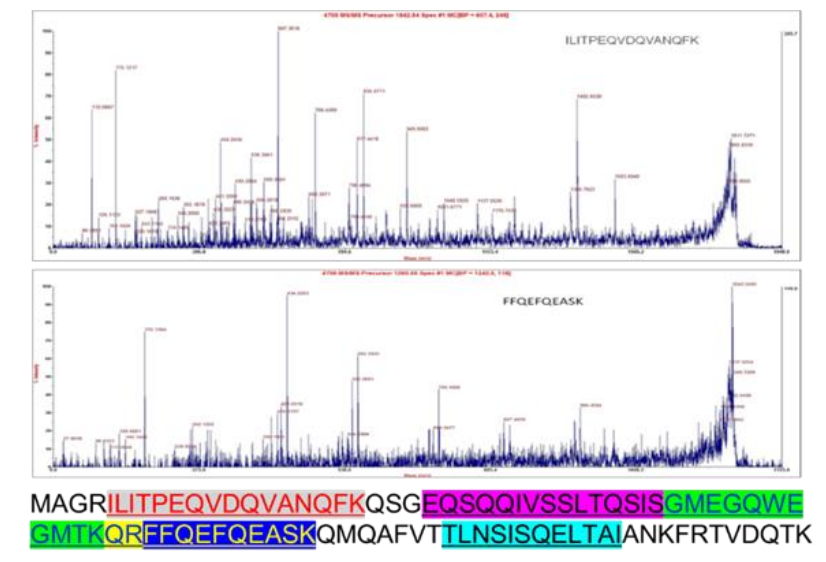

Fig. 4 Secondary mass spectra of EsxA peptides as well as the identified peptide fragments and their positions.

Note: The underlined amino acids indicate the identified sequences. The different font colors and different backgrounds represent the identified peptide fragments

\section{Induction of the plant HR and ROS burst by EsxA}

An analysis of the N. tabacum, S. lycopersicum, S. ningpoensis, and B. rapa L. ssp. chinensis plants revealed that EsxA can induce the HR in these species (Figure 5A-D). Moreover, in addition to the infiltrated leaves, EsxA also induced the ROS burst in untreated leaves growing above the infiltrated leaves (Figure 5E). In contrast, the ROS burst was not detected in the BSA-infiltrated control leaves (Figure 5F). These results suggest that EsxA has characteristics consistent with those of an elicitor.

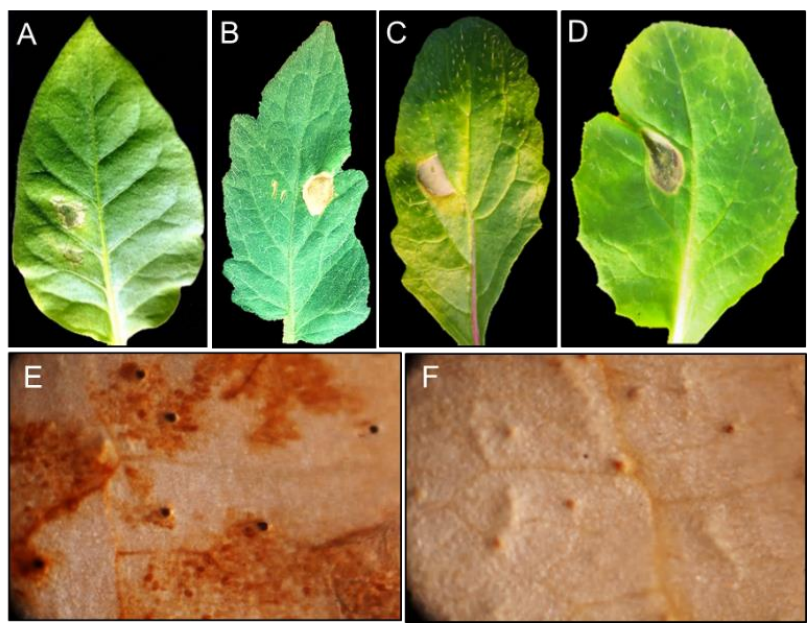


Fig. 5 Hypersensitive reaction in various plants and reactive oxygen species burst in tobacco leaves treated with EsxA.

Note: A-D: hypersensitive response in the leaves of Nicotiana tabacum, Solanum lycopersicum, Scrophularia ningpoensis, and Brassica rapa L. ssp. chinensis infiltrated with EsxA, respectively; E and F: Detection of reactive oxygen species in the tobacco leaves growing above those infiltrated with EsxA and in control leaves infiltrated with bovine serum albumin, respectively

\section{Effects of EsxA on rice seedling growth}

In the seed-bud dipping experiment, EsxA $(100 \mu \mathrm{g} / \mathrm{mL})$ significantly affected rice seedling growth, with the treatment increasing the root length by 1.35 -times $(\mathrm{F}=29.878, \mathrm{P}=0.005)$ and decreasing the shoot length by $28.8 \%(\mathrm{~F}=30.250, \mathrm{P}=0.005)$ (Figure $6 \mathrm{~A}, \mathrm{C}, \mathrm{D})$. In the seedling dipping experiment, the EsxA treatment promoted seedling growth. Specifically, the EsxA-treated roots and shoots were respectively 2.6-times $(\mathrm{F}=112.500, \mathrm{P}<0.001)$ and 1.7-times $(\mathrm{F}=38.281, \mathrm{P}=0.003)$ longer than the control roots and shoots (Figure 6B, E, F). These observations confirmed that EsxA can promote the growth of rice plants, especially the roots.

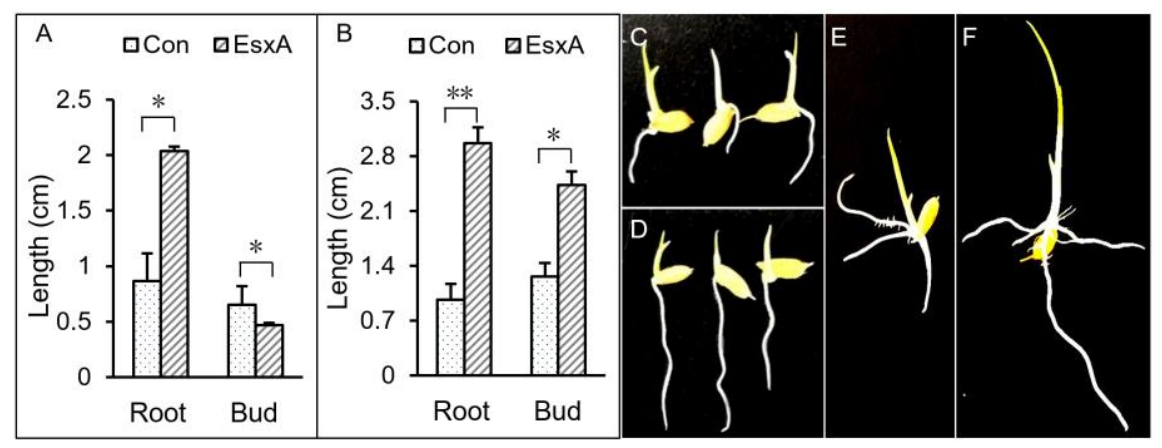

Fig. 6 Effects of EsxA on rice seedling growth.

Note: A: seed-bud dipping experiment; B: seedling dipping experiment; C and D: control and EsxA treatments in the seed-bud dipping experiment, respectively; $\mathrm{E}$ and F: control and EsxA treatments in the seedling dipping experiment. * and ** represents differences are significantly at the levels of $\mathrm{P}=0.01$ and $\mathrm{P}=0.001$, respectively.

\section{Discussion}

In this study, the EsxA gene of P. terrae strain NK3-4 was cloned. Additionally, the EsxA protein was produced in a yeast expression system and its rice growth-promoting effects were confirmed for the first time. Previous research on the EsxA gene did not involve a functional characterization in 
Paenibacillus strains. Thus, its potential role in the mechanism underlying the plant growthpromoting activities of Paenibacillus strains remained unknown. Earlier investigations on EsxA focused on its effects on the pathogenicity of animal pathogens or its induction of immune responses in disease-resistant animals (Ma et al. 2015; Zhou et al. 2013). The results of the current study imply that the mechanism regulating the plant growth-promoting effects of Paenibacillus strains, including NK3-4, may involve the secretion of EsxA. Accordingly, EsxA may be useful as a new protein elicitor that can regulate plant growth. Recent studies proved that protein elicitors can stimulate plant metabolism to modulate plant growth (Darwati et al. 2018; Shen et al. 2019). Moreover, interacting proteins that directly or indirectly bind to elicitors have been identified in plants (Mario et al. 2017). This interaction induces a series of downstream signal transduction pathways to stimulate secondary metabolic activities related to plant growth regulation (Zhao et al. 2005; Liu et al. 2018; Tang et al. 2014; Cui et al. 2017). For example, the application of a yeast elicitor reportedly enhances the production of phenolic acids and tanshinones in Salvia miltiorrhiza, while also increasing hairy root growth (Chen et al. 2001). The mechanisms by which elicitors promote plant growth are complex. In response to an elicitor, plant growth and metabolism may be affected via the cross-talk among different signaling pathways (e.g., cross-talk between the elicitor and jasmonate and between jasmonate and ethylene signaling pathways) and the interactions between these pathways and ROS as well as the integration of multiple signaling pathways and transcription factors (Cheng et al. 2018). These signaling components are connected in an elicitor signaling network and transduce elicitor signals at the transcriptional and metabolic levels, thereby influencing plant secondary metabolism to further regulate plant growth (Zhao et al. 2005; Cheplick et al. 2018).

In this study, we determined that EsxA likely contributes to the plant growth-promoting activities of specific rhizobacteria, implying EsxA may be useful as a plant growth regulator. The fact that EsxA can promote plant growth suggests certain molecular interactions occur between EsxA and plants. Future research should focus on these interactions to elucidate the EsxA-associated plant growthpromoting mechanism and possibly provide the theoretical basis for the commercial application of EsxA as a growth regulator.

\section{Abbreviations}

ACN: acetonitrile; TFA: trifluoroacetic acid; HR: hypersensitive response; BSA: bovine serum albumin; ROS: 
reactive oxygen species

\section{Authors' contributions}

Wen-qing Yu (first author) and Wen-zhi Liu (corresponding author) were the primary contributors to this study, with helpful advice from Xin Wang, Yi-cong Tang, and Gui-ping Zheng, who also participated in developing, drafting, and finalizing the manuscript. Feng-chao Yan and Dong-mei Yin helped analyze the data. All authors read and approved the final manuscript.

\section{Funding}

This work was supported by the National Natural Science Foundation of China (32060633), the Natural Science Foundation of Heilongjiang Province of China (LH2019C079), and the United Nations Industrial Development Organization (UNIDO PROJECT 180235).

\section{Availability of data and materials}

Please contact the authors for all requests.

\section{Ethics approval and consent to participate}

Not applicable.

\section{Consent for publication}

All listed authors have read the manuscript and agreed to the publication of this research.

\section{Competing interests}

The authors declare that they have no competing interests.

\section{References}

Berthet FX, Rasmussen PB, Rosenkrands I, Andersen P, Gicquel B (1998) A Mycobacterium tuberculosis operon encoding ESAT=6 and a novel low-molecular-mass culture filtrate protein (CFP-10). Microbiology, 144(11):3195-3203.

Chen H, Chena F, Chiu FCK, Lo CMY (2001) The effect of yeast elicitor on the growth and secondary metabolism of hairy root cultures of Salvia miltiorrhiza. Enzyme \& Microbial Technology, 28(1):100-105.

Cheng CH, Shen BN, Shang QW, Liu LD, Peng KC, Chen YH, Chen FF, Hu SF, Wang YT, Wang HC, Wu HY, Lo CT, Lin SS (2018) Gene-to-gene network analysis of the mediation of plant innate immunity by the eliciting plant response-Like 1 (Epl1) elicitor of Trichoderma formosa. Molecular Plant-Microbe Interactions, 31(7): 683-691.

Cheplick S, Sarkar D, Bhowmik PC, Shetty K (2018) Improved resilience and metabolic response of transplanted blackberry plugs using chitosan oligosaccharide elicitor treatment. Canadian Journal of Plant Science, 98(3): 717-731.

Cui SC, Tang XL, Qiu DW, Yang XF (2017) Function of a binding protein Nbnrp 1 in fungal elicitor PecD1-induced resistance in Nicotiana benthamiana. Acta Phytopathologica Sinica, 47(1): 92-100. Chinses article with English abstract.

Darwati I, Manohara D, Rohimatun, Nurhayati H (2018) The application of biotic elicitor on Artemisia annua L. to increase artemisinin content. IOP Conference Series Earth and Environmental Science, 102(1): 012013.

Liu J, Liu B, Chen SF, Gong BQ, Chen LJ, Zhou Q, Xiong, F, Wang, ML, Feng DR, Li JF, Wang HB, WangJF (2018) A Tyrosine phosphorylation cycle regulates fungal activation of a plant receptor Ser/Thr kinase. Cell Host \& Microbe, 23(2): 241-253. 
Ma Y, Keil V, Sun J (2015) Characterization of mycobacterium tuberculosis EsxA membrane insertion: roles of N- and C-terminal flexible arms and central helix-turn-helix motif. Journal of Biological Chemistry, 290(11): 7314-7322.

Mario G, Nélida, Celedonio (2017) The Botrytis cinerea elicitor protein BcIEB1 interacts with the tobacco PR5-family protein osmotin and protects the fungus against its antifungal activity. New Phytologist, 215(1): 397.

Pollock JM, Andersen P (1997) The potential of the ESAT-6 antigen secreted by virulent Mycobacteria for specific diagnosis of tuberculosis. Journal of Infectious Diseases, 175(5): 1251-1254.

Schulthess B, Bloes D A, Berger-Bächi B (2012) Opposing roles of $\sigma^{\mathrm{B}}$ and $\sigma^{\mathrm{B}}$-controlled SpoVG in the global regulation of esxA in Staphylococcus aureus. BMC Microbiology, 12:17.

Shen YR, Li JW, Xiang JL, Wang JQ, Yin KD, Liu Q (2019) Isolation and identification of a novel protein elicitor from a Bacillus subtilis strain BU412. AMB Express, 9(1): 117.

Tang X, Wu WX, Han L, Yang XF (2014) Screening of interacting proteins with fungal elicitor PevD1 by yeast two hybrid system and high expression of recombinant in E. coli. Biotechnology Bulletin (10): 113-118. Chinese article with English abstract.

Ulrichs T, Munk ME, Mollenkopf H, Behr-Perst S, Colangeli R, Gennaro ML, Kaufmann SH(1998) Differential T cell responses to Mycobacterium tuberculosis ESAT6 in tuberculosis patients and healthy donors. European Journal of Immunology, 28(12): 39493958.

Yi YY, Zhao YN, Ma PR, Li B, Su Y (2018) Expression and immunogenicity analysis of EsxA protein of Staphylococcus aureus isolated from cow milk. Chinese journal of biotechnology, 34(5): 694-702. Chinese article with English abstract.

Yu WQ (2019) Promoting-growth and defending-diseases mechanism of Paenibacillus terrae NK3-4 in paddy rice. Heilongjiang Bayi Agricultural University. Chinese article with English abstract.

Yu WQ, Liu WZ, Yan FC, Li HY, Zheng GP, Li DP, Zheng AB, Zhao TT, He D, Jiang H, Yan BW, SUI WZ, Wang P (2019a). Application of Paenibacillus terrae protein EsxA as a biological control agent for rice blast. China, CN109526985A, 2019-0329.

Yu WQ, Zheng GP, Qiu DW Yan FC, Liu WZ, Liu WX (2019b) Biocontrol of rice blast by Paenibacillus terrae NK3-4, a $\beta-1$, 3glucanase producing strain. Biological Control, 129(2): 92-101.

Zhao J, Davis LC, Verpoorte R (2005) Elicitor signal transduction leading to production of plant secondary metabolites. Biotechnology Advances, 23(4): 283-333.

Zhou H, Du H, Zhang H, Shen H, Yan R, He Y, Wang M, Zhu X (2013) EsxA might as a virulence factor induce antibodies in patients with Staphylococcus aureus infection. Brazilian Journal of Microbiology, 44(1): 267-271. 